(C) Dr W. Junk Publishers, Dordrecht - Printed in the Netherlands

\title{
The predictability of biological populations and communities: an example from the meiobenthos
}

\author{
Peter M. J. Herman \& Carlo Heip \\ Marine Biology Section, Zoology Institute, Rijksuniversiteit Gent, Ledeganckstraat 35, B-9000 Gent, \\ Belgium
}

Keywords: benthos, time series, monitoring, prediction, copepods

\begin{abstract}
The predictability of temporal changes was analysed in the population density of three meiobenthic copepod species, and for three parameters characterizing this community. For Paronychocamptus nanus and Tachidius discipes a large part of the variation in time scales longer than 1 year is explainable as cyclic factors. In $P$. nanus clear cyles with periods of 2 years and 1.5 years were found. These cyclic factors can be extrapolated for prediction. In Canuella perplexa almost all the variation was due to unpredictable long-term drift. Community parameters are generally better predicted than population densities. In our data set total density of the copepods was the best parameter to monitor. Monitoring does not necessitate a strict sampling scheme; irregular quarterly sampling from the $P$. nanus series showed that the essential features of the series were still discernible.
\end{abstract}

\section{Introduction}

Correct assessment of the biological consequences of pollution in coastal waters demands prior and adequate understanding of the scales and causes of natural ecological variation (COST 47 Activity Report 1983). Predictability of monitored variables chosen to describe the community is a central assumption of ecological monitoring strategies. Effects of pollution can only be inferred when the variates differ significantly from what is expected based on previous experience; that is, when the observation(s) fall(s) outside the predicted range.

Ideally, prediction should be based on a complete understanding of the intricate ecological interactions governing the dynamics of populations and communities, but this is hardly possible. However, even when the causes of variation are unknown or unquantified, prediction may still be possible on a purely statistical basis. For example, it is not necessary to understand the laws governing the movements in the planetary system to predict when the sun will rise tomorrow. When the variation in a variable is (partly) regular, this regularity can provide the basis for prediction.

Populations are variable in time and space. Both sources of variation must be studied for monitoring purposes. Here we will consider temporal variability of meiobenthic copepods from a shallow brackish-water pond. This environment has some disadvantages: large temperature fluctuations and a long-term trend in salinity. However, both can be quantified and considered as forcing functions. Sometimes catastrophic events occur: ice formation or drying. On the other hand there is no advection, a factor which has recently been shown to be of importance for meiofauna (Palmer, 1984), and temporal variability is much larger than spatial variability (Heip \& Engels, 1977). As is typical for the meiofauna (Warwick, 1984), reproduction is much more predictable than for most macrofauna populations. The phenology of reproduction, measured as the date when the populations start to increase exponentially, is very constant from year to year (Heip, 1980a).

Harpacticoid copepods are small organisms, 
around $1 \mathrm{~mm}$ or less long and weighing between 0.5 and $5 \mu \mathrm{g}$ dry weight. Development times are typically around two - three weeks and they are shortlived. One therefore expects that the relevant timescales will be in the order of less than to about one year. This argument has frequently been used in favour of using harpacticoid copepods in pollution studies (Heip, 1980b).

In previous studies of this community we have shown that long-term periodicity is important, at least in some of the populations. The time series were studied by Maximum Entropy Spectral Analysis (Herman \& Heip, 1983a; Heip \& Herman, 1985). The highest peaks in the spectra were often found for periodicities of two to five years. These results differ basically from those reported for estuarine copepods in South Carolina, USA by Coull (1985) and Coull \& Dudley (1985), who found no periodicity longer than one year.

In this paper we will address the following questions:

a) How predictable (and how truly cyclical) is the temporal variation on time scales in excess of 2 months in our populations and communities?

b) What parameters can be used for prediction of future states of the system?

c) What is the sampling effort required?

\section{Material and methods}

The sampling site and techniques are described in many previous papers (e.g. Heip, 1980a). The time-series is based on fortnightly samples from August 1968 till December 1976. One sample was analysed on each date. Copepod species density and population composition were determined, from which biomass and respiration were calculated. Species richness is low and attention in this paper will be focused on the three dominants Paronychocamptus nanus, Tachidius discipes and Canuella perplexa. For more information on these species we refer to Heip (1980a), Herman \& Heip (1983a, b; 1985) and Herman, Heip \& Guillemijn (1984).

The analysis in this paper is independent from the spectral analysis performed earlier. Here we use a simple but very robust procedure, described by Kendall (1976). The data series were grouped per two months, so that, e.g. the 'Jan.-Feb.' value of
1973 is the mean from all the samples that were taken in these two months. The series is split into three elements: a) a long-term trend (which can further be split into a linear trend and more or less regular fluctuations around it); b) cyclic components (including seasonal effects); c) irregular or random effects. These elements are analysed after logtransformation of the series (the rationale being that multiplicative effects are more important than additive effects).

Kendall's (1976) method for the extraction of seasonal effects proceeds as follows:

a) a moving average with a length of one year is calculated.

b) this long-term trend is subtracted from the series

c) from the residual series seasonal components are calculated by taking the average values over the first two months of each year, over the second two months of each year and so on. These six 'raw' cyclic effects are also averaged, and their average is subtracted from the six values. These final values express the seasonal effects, and are subtracted from the residuals. These new residuals are then checked to see if any periodicity remains.

Examination of the residuals of several of our series showed that an important cyclicity with period 2 years remained. The analysis was, in these cases, adapted to extract 2 -yr. cyclic effects (and, at the same time, all effects with periods of an integer fraction of 2 years, i.e. 1 year, 0.5 year etc.). In this analysis we calculated from the original series a 2-yr. moving average, instead of a 1-yr. moving average, and proceeded to extract 12 raw and adjusted cyclic components (analogous to the seasonal components) by averaging the residuals of the first, second,..., twelfth two-month interval. Thus an average was made of the residuals in Jan.- Feb. of every second year, Mar--Apr. of every second year, etc. The seventh period is again Jan.-Feb., the eighth again Mar--Apr., but these are other cyclic components than the first six values.

For the density of Paronychocamptus nanus, and the community parameters influenced by this density, a periodicity of 1.5 year was found in the residuals after extraction of 2 years period components. This periodicity was further subtracted in a similar way, whereafter the residuals were irregular (note that the subtraction of the 1.5 year periodicity was performed after the extraction of the 2 years 
period components, and did not replace it, as the 2 year component extraction replaced the seasonal component extraction).

To check whether a series is random or irregular one studies the correlogram of the series, constructed on the basis of autocorrelation (see Platt \& Denman, 1976), the correlation of the series with itself at a certain time-lag.

When a series is decomposed in this way, it can be used in forecasting: by reassembling the trend, the seasonal and other cyclic effects and the oscillations around the trend we can project the series forward in time.

\section{Results}

\section{Paronychocamptus nanus}

Figure 1A shows the autocorrelation values of the density of $P$. nanus after extraction of a $2 \mathrm{yr}$. moving average. It is apparent that cyclical elements are present in the series. These were not removed by extraction of the average seasonal cycle (average within-year effect). We therefore proceeded to extract a cyclic component with period $2 \mathrm{yr}$. from the series. This component is highly asymmetric between one year and the next (Fig. 2C). The residuals after extraction of the 2 yr. moving average (Fig. 2B) and the 2 yr. period cyclical component are shown in Fig. 2D. It immediately appears from inspection of the data and the correlogram (Fig. 1B) that another cyclic phenomenon, with period $1.5 \mathrm{yr}$., dominates this residual series. The $1.5 \mathrm{yr}$. component was extracted, and added to the 2 yr. component (Fig. 2E). A kind of interference pattern is produced, that mimicks very well the detrended series. The final residuals are shown in Fig. 2F. This series is produced by subtracting from the original series (Fig. 2A) the 2 yr. moving average (Fig. 2B) and the summed cyclic components (Fig. 2E). Note that, because we do not force the 'cyclic components' to take the form of sine waves, cycles with frequencies that are integer multiples of the basic frequencies, are also filtered out. Thus the extraction of a cyclical component with period 2 yr., in principle also extracts components with periods $1 \mathrm{yr}$., $2 / 3$ yr., $1 / 2 \mathrm{yr}$., $2 / 5 \mathrm{yr}$., $1 / 3 \mathrm{yr}$.

The correlogram of the final residuals (Fig. 1C) reveals no particular structure left. The division of
Detrended
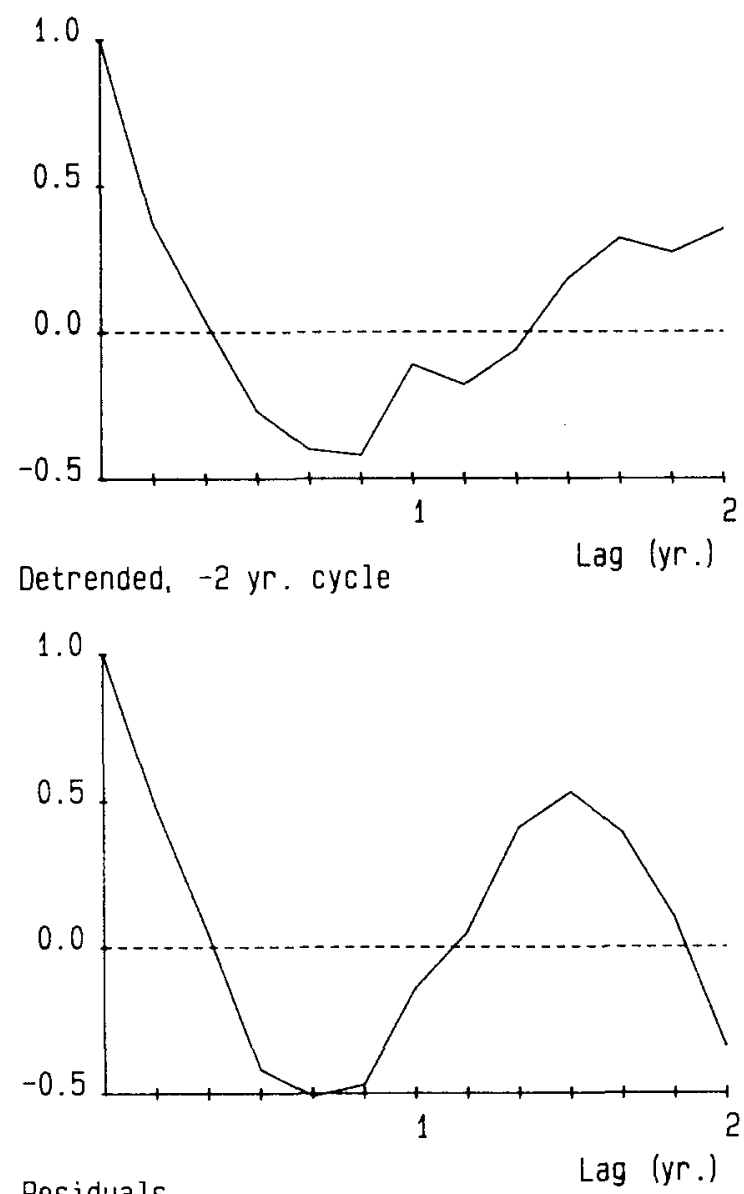

Residuals

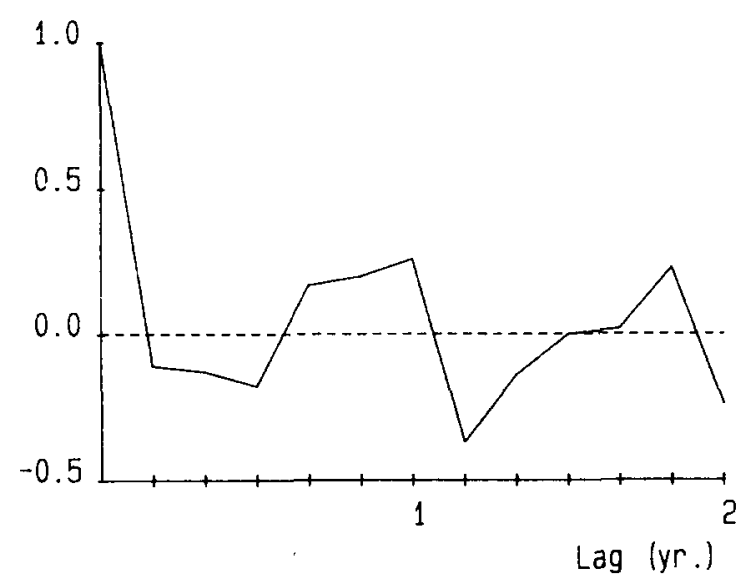

Fig. 1. Density of Paronychocamptus nanus: autocorrelogram of the original series (Fig. 1A), after extraction of the 2-years period components (Fig. 1B), and residuals after further extraction of the 1.5 year period. 
In (density)

Detrended, - 2-yr. Cycle
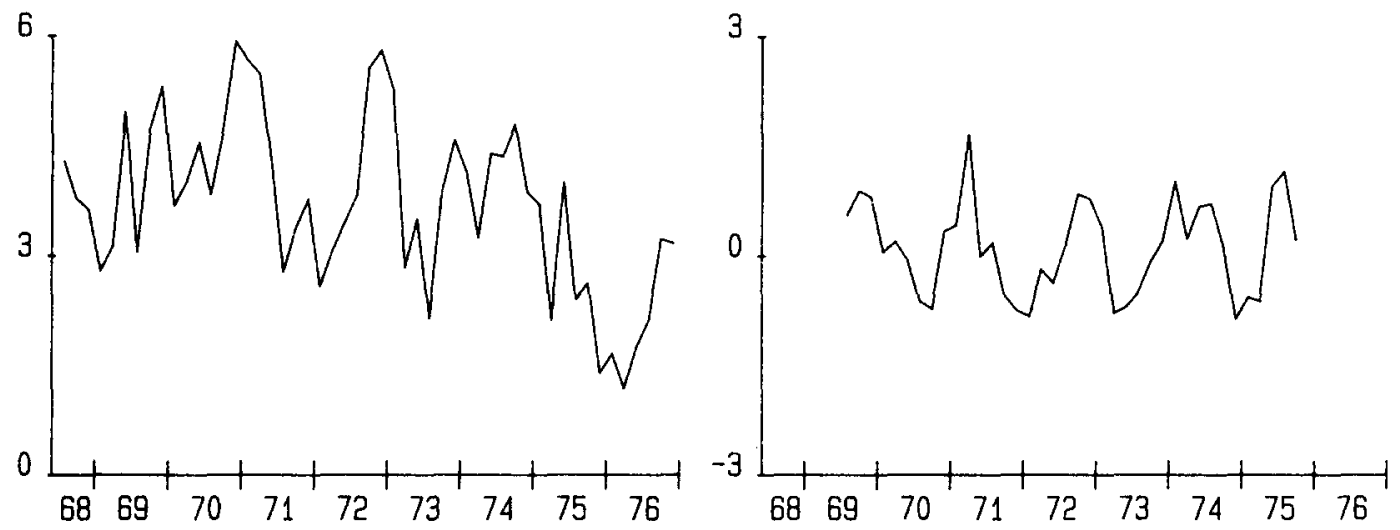

2-yr. Moving Average

$2-y r .+1.5-y r$. cycles
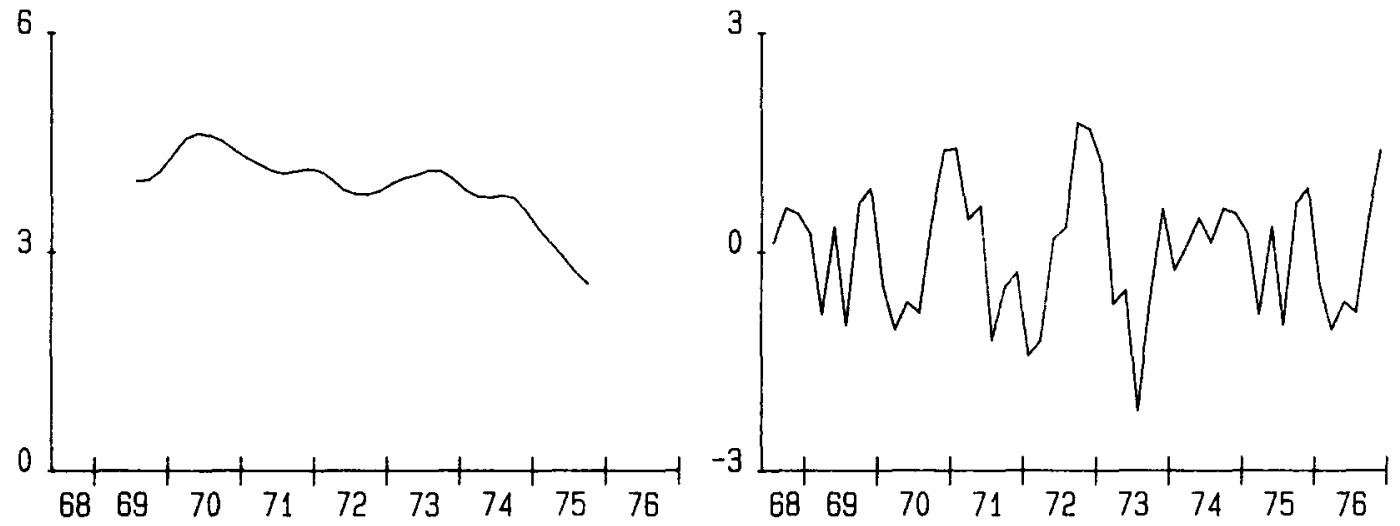

2-yr. cycle

Final residuals
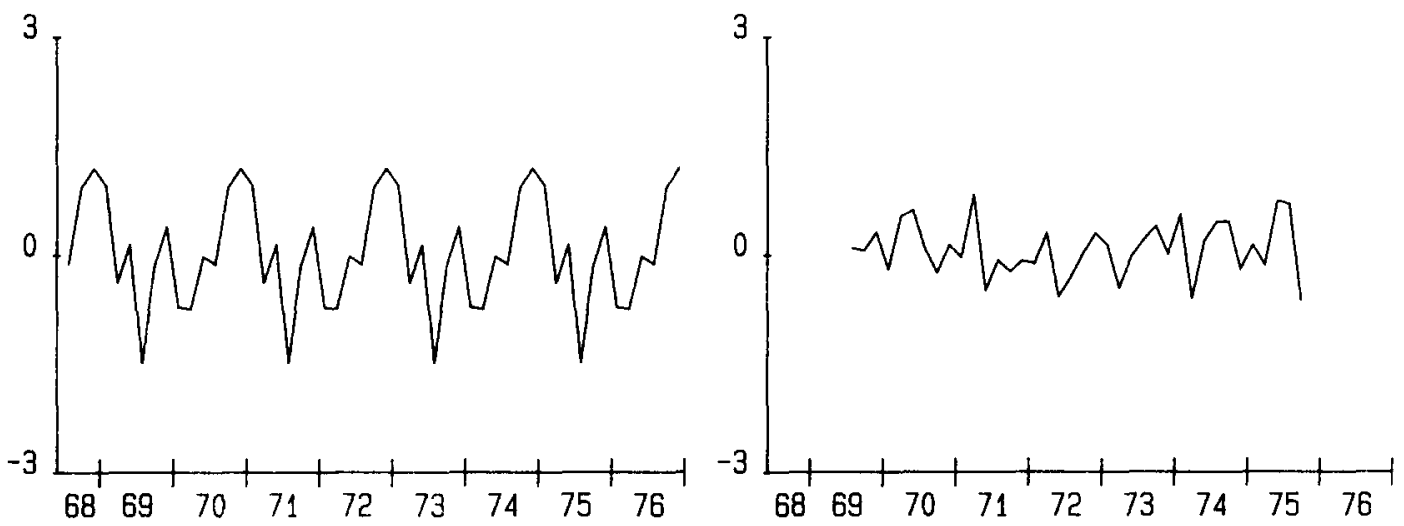

Fig. 2. Density of Paronychocamptus nanus: original series (Fig. 2A), 2-yr. moving average calculated from this series (Fig. 2B), extracted 2-yr. cycle (Fig. 2C), residuals after extraction of the 2-yr. moving average and the 2-yr. cycle (Fig. 2D), sum of the 2-yr. and 1.5-yr. cycles (Fig. 2E), and final residuals (after extraction of the 2-yr. moving average, and the 2-yr. and 1.5-yr. cycles). 
the Sums of Squares of the original series between the different components is shown in Table 1.

The SS of the different components add to a higher amount than the SS of the original series, indicating that there is a (small) negative covariance between the components.

A relatively large proportion of the variance of the original series (appr. 75\%) is explained by the summed cyclic components. For predictive purposes, these can in principle be extrapolated to the future. As a test we estimated the harmonic component from the series between 1968 and 1974, thus neglecting the last two years. It is seen from Fig. 3 that the pattern coincides reasonably well with that estimated for the whole series (Fig. 2E).

Table 1. 7-years series of the density of Paronychocamptus nanus: division of the Sums of Squares of the original series between the different components. The first and last year of the series have been left out, since we have no values for most components here.

\begin{tabular}{lr}
\hline Series & \multicolumn{1}{c}{ SS } \\
\hline Original series ('69-'75) & 40.33 \\
Moving average & 8.20 \\
2 yr. cycle & 22.53 \\
1.5 yr cycle & 11.00 \\
Residuals & 5.32 \\
\hline
\end{tabular}

$2-y r .+1 \cdot 5-y r$. cycles

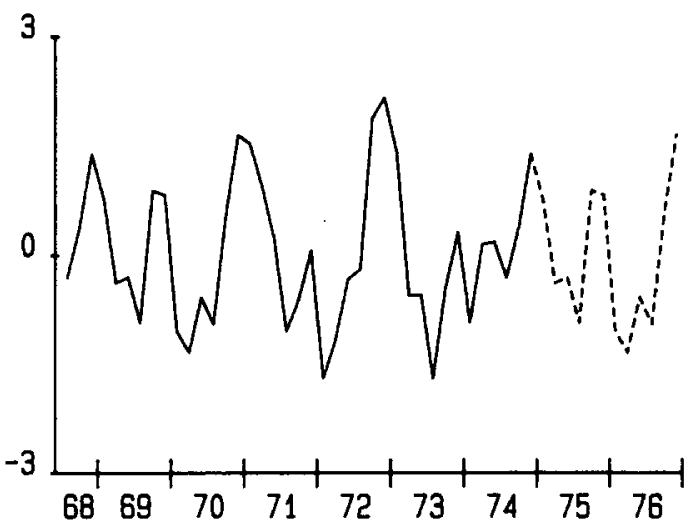

Fig. 3. Density of Paronychocamptus nanus: Cyclic components (sum of 2-yr. cycle and 1.5-yr. cycle) determined on part of the original series: 1975 and 1976 are left out of the analysis. Compare with Fig. 2E.

\section{Other series}

As in $P$. nanus, the only identifiable structure in the other series are the cycles that were already revealed by the spectral analysis (Herman \& Heip, 1983a; Heip \& Herman, 1985). In Canuella perplexa the spectrum was largely dominated by a peak in the very low frequencies (the peak value corresponded to a period of $3.8 \mathrm{yr}$.). Correspondingly, we find very little structure in the autocorrelogram after extraction of the trend (Fig. 4). A very small (yearly) seasonal factor was found (Fig. 5B). Inclusion of the years 1968 and 1969 has a profound influence on the interpretation of the long-term trend (dashed line in Fig. 5A). From 19.70 onwards a kind of cycle, such as shown by the spectral analysis, can be seen. However, as the species was completely absent in the winter '68-'69, this pattern is abruptly changed. C. perplexa was also completely absent in 1980 . The population seems to crash and be refounded at irregular intervals, which makes prediction of its numbers a very difficult task.

For Tachidius discipes the spectrum is largely dominated by a peak on $1 \mathrm{yr}$. Small peaks correspond to periods of $2 \mathrm{yr}$., $1 / 2 \mathrm{yr}$. and $1.5 \mathrm{yr}$. (note that MESA does not provide a test for the statistical significance of the peaks). Extraction of components with period 2 yr. or integer fractions thereof explains about $70 \%$ of the variance of the

\section{Detrended}

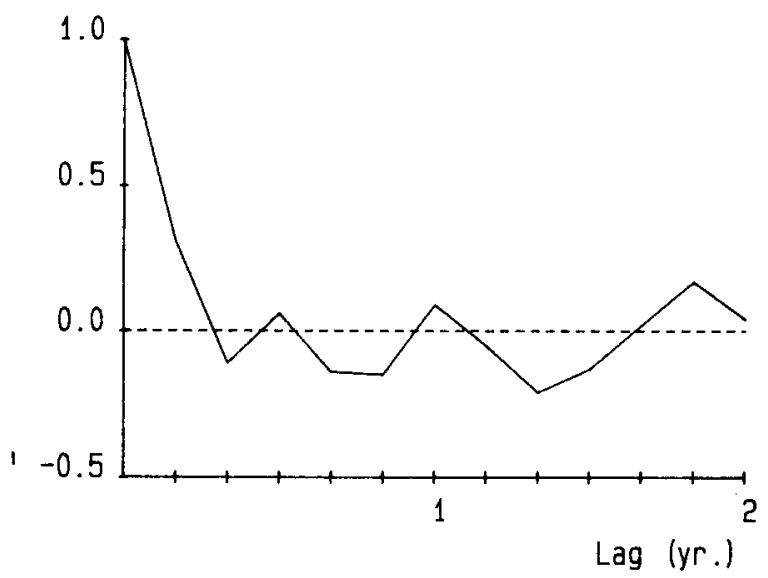

Fig. 4. Density of Canuella perplexa: autocorrelogram after extraction of a 1-yr. moving average from the series. 
ln (density)

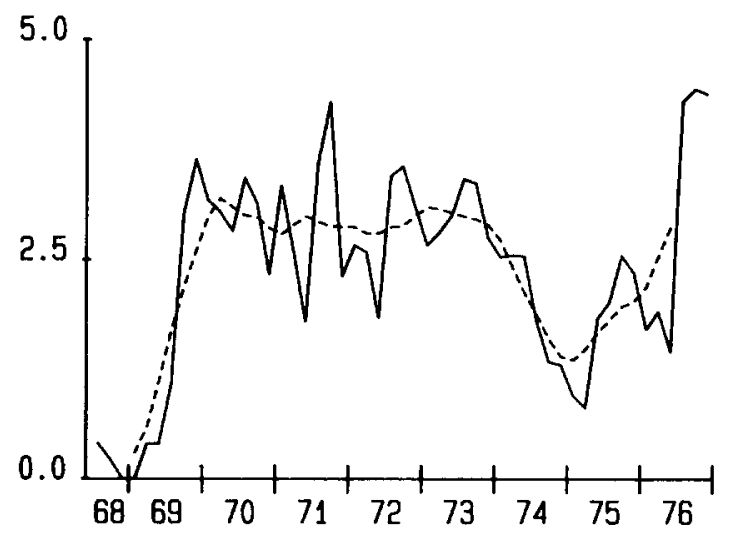

1-yr. cycle

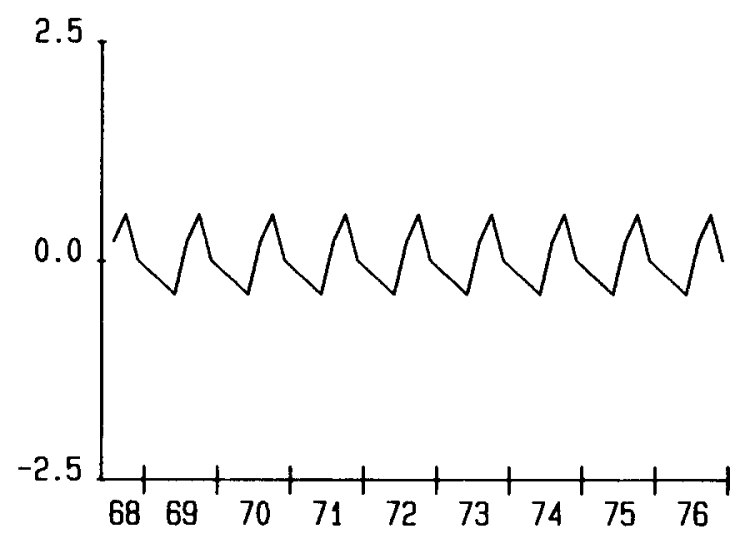

Fig. 5. Density of Canuella perplexa: original series (Fig. 5A, full line), with superimposed 1-yr. moving average (dashed line). Extracted 1-yr. cycle is shown in Fig. 5B.

detrended series. (Fig. 6). The residual variance is further reduced by one third after the extraction of a 1.5 yr. period component. Trend is relatively unimportant (Fig. 6A: dashed line). Trend and residual variance contain about $25 \%$ of the variance of the original series. In fact, this series is very predictable, except for the unusually high peak of 1975 , and the second peak in 1976, which is, however, attributable to a special event (part of the pond dried out in this very warm summer).

\section{Community parameters}

As we stressed earlier (Heip \& Herman, 1985) the
In (density)

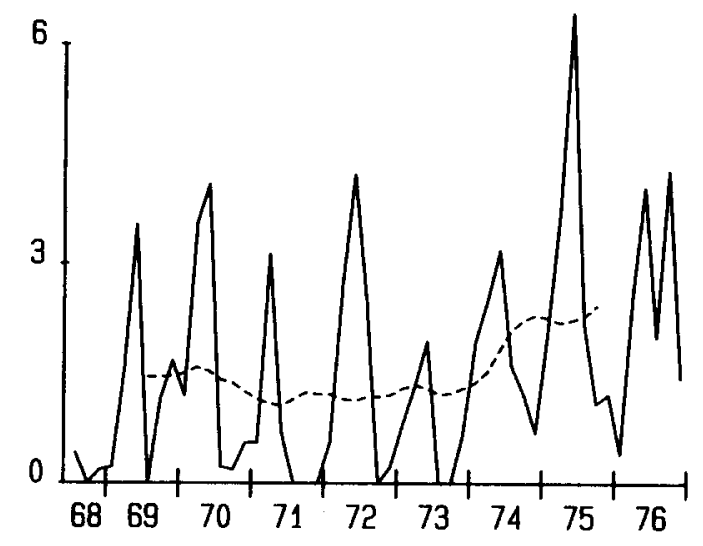

2-yr. cycle

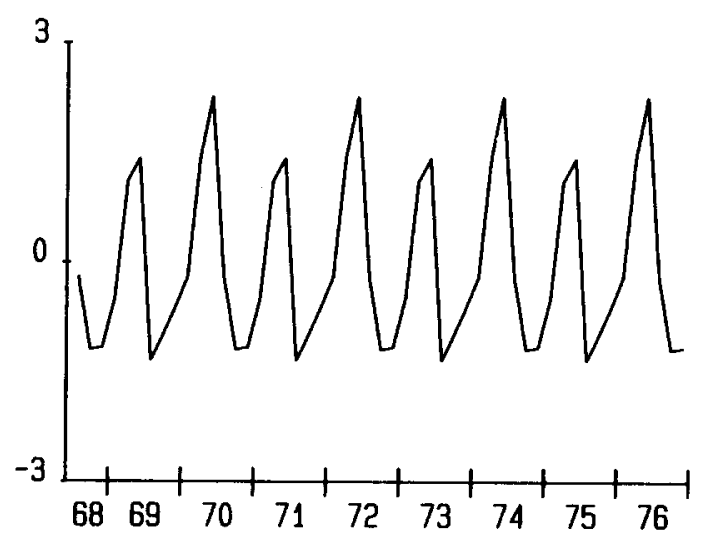

Fig. 6. Density of Tachidius discipes: original series (Fig. 6A, full line), with superimposed 2-yr. moving average (dashed line). Extracted 2-yr. cycle is shown in Fig. 6B.

community parameters 'total density', 'total biomass' and 'community respiration' show little or no trend (Figs 7, 8, 9: dashed lines). This is especially so for respiration, the most stable parameter of the three. The community parameters are also much more stable than the densities of the constituent species in another sense. The coefficients of variation $(\mathrm{CV}=100 \mathrm{~s} / \overline{\mathrm{x}})$ are much smaller than for the population densities (Table 2).

About an equal fraction of the SS (2/3) in total density and in respiration is explained by cyclic factors (periods 2 yr. and 1.5 yr. summed). In biomass this is much less $(<1 / 4)$ and this series is almost completely non-seasonal. 
In (Total Density)

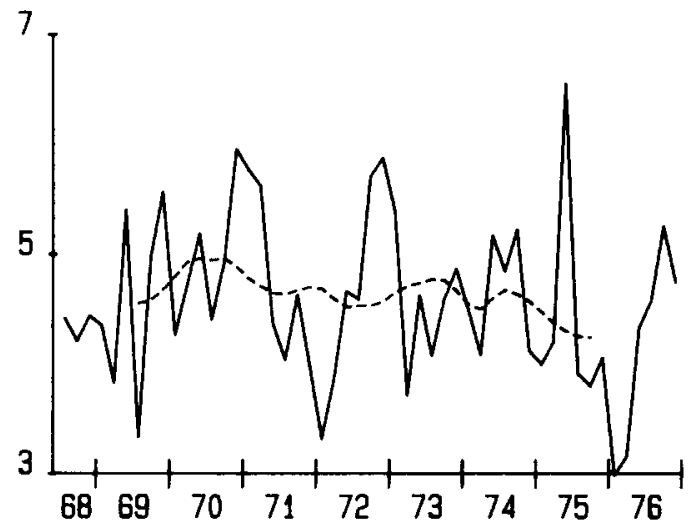

Fig. 7. Total copepod density in the community studied: original series (full line) and 2-yr. moving average (dashed line).

\section{In (Biomass)}

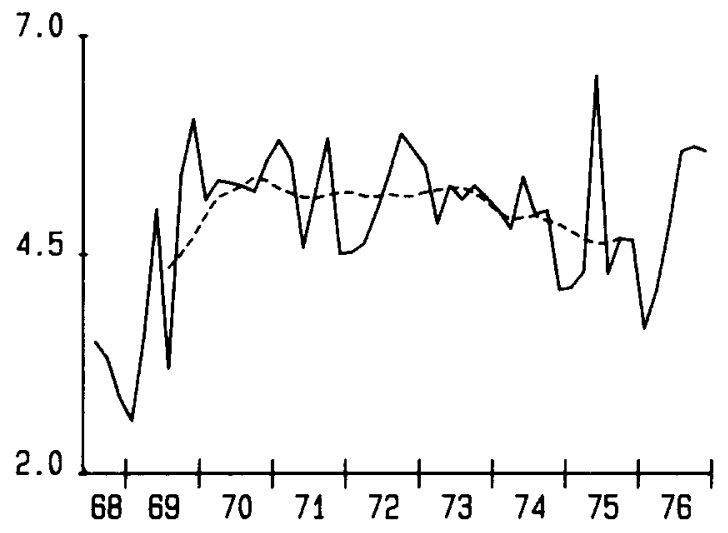

Fig. 8. Total biomass of the copepods in the community studied: original series (full line) and 2-yr. moving average (dashed line).

Table 2. Comparison of the coefficient of variation $(\mathrm{CV}=$ $\mathrm{s} / \mathrm{x}^{*} 100 \%$ ) between the density series of three meiobenthic copepods, and three parameters of the meiobenthic copepod community.

\begin{tabular}{ll}
\hline Series & CV (\%) \\
\hline P. nanus density & 32 \\
T. discipes density & 94 \\
C. perplexa density & 49 \\
Total density & 17 \\
Biomass & 17 \\
Respiration & 15 \\
\hline
\end{tabular}

\section{In (Respiration)}

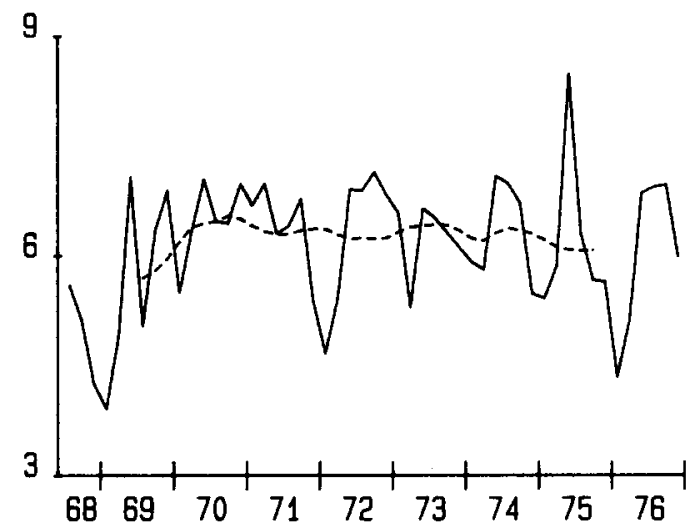

Fig. 9. Total respiration of the copepods in the community studied: original series (full line) and 2-yr. moving average (dashed line).

\section{An inefficient sampling scheme for P. nanus}

Due to storms, unavailability of research vessels, broken cables, damage to the winches, administrative or financial problems, lack of time and other miscellaneous problems, it is not always possible to follow a strict sampling scheme (e.g. monthly) for a station at sea. As an example we took the roughly seasonal sampling scheme that was realized for a few stations in the Belgian coastal zone between 1977 and 1983 (Herman R., unpublished). We transposed the dates 7 years back, and took from the fortnightly series of Dievengat samples of $P$. $n a$ nus the one that was next to each date. These samples were subsequently taken as representative for the season in which they fell (Winter, Spring, Summer, Fall). Values for unsampled seasons were linearly interpolated.

The resulting series is shown in Fig. 10 (Compare with Fig. 2). Surprisingly, the major features of the original series are well preserved. After extraction of the trend, the 2 yr. periodicity (Fig. 10B) is apparent. It is very similar in form to that extracted from the whole series (Fig. 2C). Even the $1.5 \mathrm{yr}$. cycle can be clearly seen in the residuals. The compound harmonic part of the series (Fig. 10C) is very comparable to the one in the complete series (compare Fig. 2E). 
In (density)

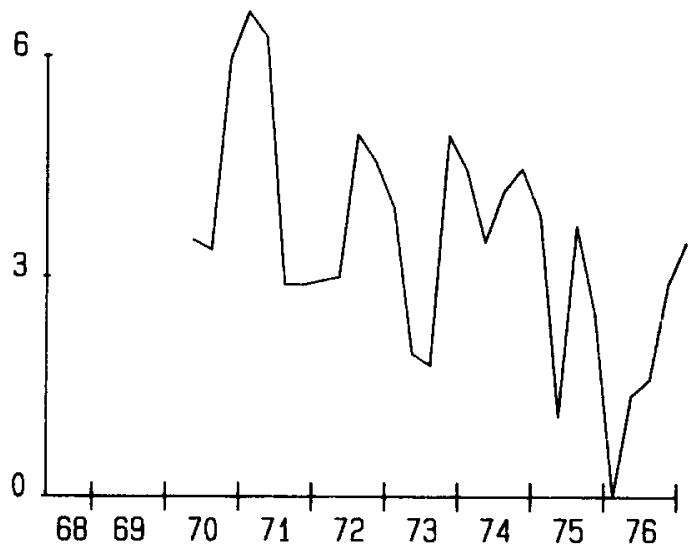

2-yr cycle

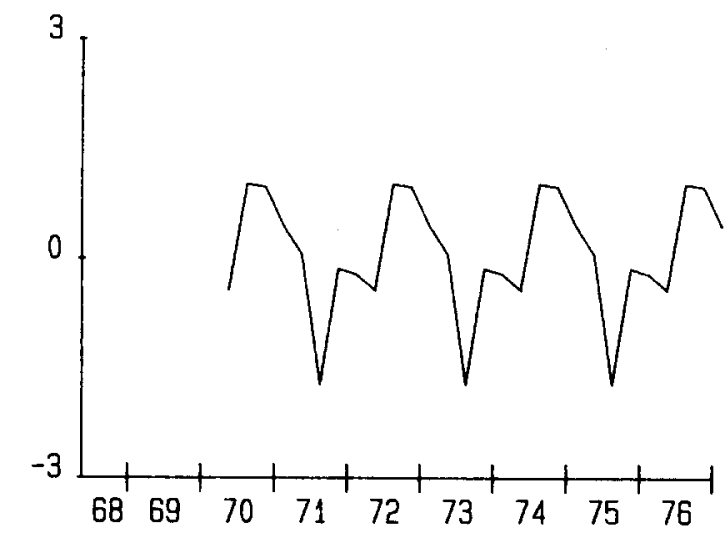

$2-y r .+1.5-y r$. cycles

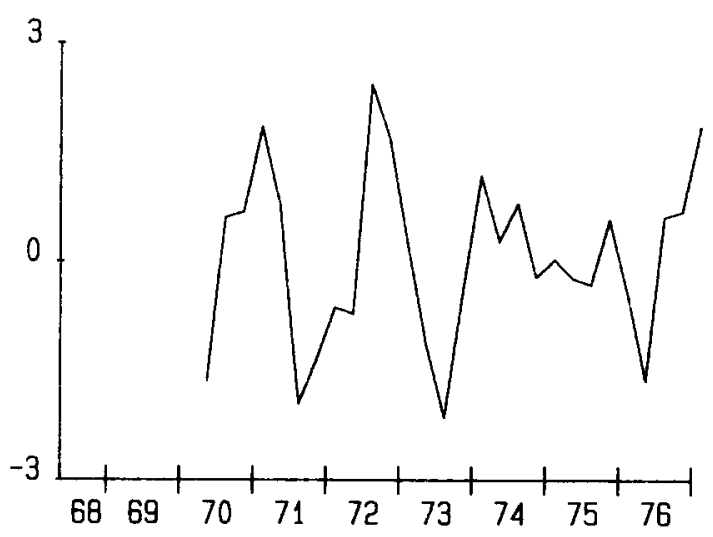

Fig. 10. Paronychocamptus nanus: samples taken from the original series according to a (realized) irregular sampling scheme (see text). A: density, B: extracted 2-yr. cycle, C: sum of the extracted $2-y r$. and 1.5 yr. cycles.

\section{Discussion}

Of the three population density time-series discussed here, two have an important part of their variance explained by cyclic terms. This part may, in principle, be usable for prediction purposes. This is certainly the case for seasonal ( 1 yr.) factors. The mechanism underlying seasonal variation is obvious, and one can be sure about the exact period, and the truly cyclic nature of the phenomena. It is, however, less sure for 2 yr. periods. The succession of high peaks by lower ones the next year, higher again the next year etc. may be produced by chance. However, if the peak's height is purely random, only in one case out of 64 an alternating pattern will be produced in 8 successive years. Therefore we consider the 2 yr. period cycle in $P$. nanus to be most likely a truly cyclic phenomenon.

What to do, however, with a 1.5 yr. period cycle? A 1.5 yr. period swing is undoubtedly present in the data. The problem in interpreting it as a longlasting, true cycle is that we cannot conceive of a mechanism producing it. Moreover, although the 2 yr. and 1.5 yr. period cycles are observed 3 to 4 times in the series, the 'interference pattern' between them is repeated only once every $6 \mathrm{yr}$. This is about equal to the period of observation.

In contrast to the situation for $P$ nanus and $T$. discipes, in the $C$. perplexa series almost no cycling was present, compared to the importance of the long-term trend.

In all the series studied, no particular structure was left after extraction of cyclic components and trend. Trend in particular may render prediction difficult. We can take the trend in $P$. nanus as an example. This can be decomposed in a linear trend with negative slope, and a long-term swing around this line. MESA - spectral analysis indicated that the dominant period in this swing is $4.6 \mathrm{yr}$. (Herman \& Heip, 1983; Heip \& Herman, 1985). Howev$\mathrm{er}$, the determination of the period is unsure, as is the answer to the question if a cycle is really present. Obviously, extrapolation to the future depends on this answer.

The same is true for the linear trend. Extrapolation of this trend yields highly unrealistic values for 1980. The mean density in this year was about 350 ind. per $10 \mathrm{~cm}^{2}$ (Herman \& Heip, 1985), whereas the predicted value of the trend corresponds to about 9.5 ind. per $10 \mathrm{~cm}^{2}$. Is the line- 
ar' trend part of an oscillation with a very long period, or is there random or pseudocyclic fluctuation in the yearly mean densities? One would need at least 20 year of data in order to choose between the alternatives.

Based on the data between 1968 and 1974, one would hardly suppose a negative trend at all. The best fitting line on the moving average between mid-1969 and mid-1973 has a slope of -0.10 per year, compared to -0.20 per year for the whole series.

The difficulty of interpreting patterns in trend is also illustrated by the $C$. perplexa series. MESA revealed a $3.8 \mathrm{yr}$. periodicity in the data between ' 70 and 76. This can still be found back in the trend (Fig. 5A), but the '68-'69 data clearly distort this pattern. Similarly, the harmonic extrapolation of the 3.8-years period 'cycle' would not have predicted the disappearance of the population in 1980 .

Gray \& Christie (1982) postulated that oscillations with periods of $6-7,10-12, \ldots$ yr. may be a rule in marine populations. However, the evidence for this is still very scarce. The mechanisms they propose are unlikely to have any influence in an enclosed pond such as the Dievengat (except, maybe, for the (in)famous 'sunspot cycle'). On the other hand, the fact that cyclicity is the only pattern emerging on shorter terms, may provide some kind of justification for the search for cycles, even on the longer time scales.

Heip \& Herman (1985) showed that the community parameters had less linear trend and less longterm fluctuations than the densities of the constituent species. This greater stability of community parameters is also shown in the coefficients of variation (Table 2). Stability is most pronounced in the 'functional' parameter respiration. Considering the whole system in which we sampled the meiobenthic copepods, the function of the 'copepod black box' is probably best represented by the total respiration, as it is highly correlated with production (Herman et al., 1984). Most of the variation in respiration is explained by cyclic components. Trend is almost completely absent, and the residual variance is small. These features make it a very predictable series, and a likely candidate for monitoring purposes. There are two drawbacks, however: 1) it is not known how sensitive a measure this parameter is for changes in the environment: will it remain unchanged even after dramatic changes in the com- munity? 2) it is not easily measured. Total density and biomass are much easier to measure. If the sampling scheme is intensive enough to estimate seasonal or other cyclic components, total density seems to be the preferable parameter.

As shown by our exercise on $P$. nanus, even a very inefficient sampling scheme was able to reveal most of the structure in this relatively complex series. Monitoring does not seem to depend too heavily on a close interval sampling scheme. As a rule of thumb we would suggest that three to four years of sampling seasonally will already produce the most obvious characteristics of the time-series. This is longer than suggested by Coull \& Dudley (1985). It should be noted, however, that the populations studied by these authors exhibit less long-term changes (such as the two-year cycles shown here). A too short sampling time will miss these components, which are shown here to be important in some cases. Whether this holds for other groups besides copepods remains to be studied.

\section{Acknowledgments}

Both authors acknowledge a grant of the Belgian National Fund for Scientific Research (NFWO). Part of this research was sponsored through the grant FKFO-2.9007.82 'Systematics and ecology of marine organisms'. We thank Wies Gyselinck for technical assistance.

\section{References}

Coull, B. C., 1985. Long-term variability of estuarine meiobenthos: an 11-year study. Mar. Ecol. Prog. Ser. 24: 205-218.

Coull, B. C. \& B. W. Dudley, 1985. Dynamics of meiobenthic copepod populations: a long-term study (1973-1983). Mar. Ecol. Prog. Ser. 24: 219-229.

Gray, J. S. \& H. Christie, 1983. Predicting long-term changes in marine benthic communities. Mar. Ecol. Prog. Ser. 13: $87-94$

Heip, C., 1980a. The influence of competition and predation on production of meiobenthic copepods. In: K. R. Tenore \& B. C. Coull (eds), Marine benthic dynamics. The Belle W. Baruch Library in Marine Science, no. 11. University of South Carolina Press, pp. 167-177.

Heip, C., 1980b. Meiobenthos as a tool in the assessment of the quality of the marine environment. Rapp. P.-v. Réun. Cons. Int. Explor. Mer 179: 182-187.

Heip, C. \& P. Engels, 1977. Spatial segregation in copepod species from a brackish water habitat. J. exp. mar. Biol. Ecol. 26: $77-96$. 
Heip, C. \& P. M. J. Herman, 1985. The stability of a benthic copepod community. In: P. E. Gibbs (ed.), Proceedings of the 19th European Marine Biology Symposium. Cambridge Univ. Press, pp. 255-263.

Herman, P. M. J. \& C. Heip, 1983a. Long-term dynamics of meiobenthic populations. Oceanologica Acta, Actes 17 European Marine Biology Symposium, pp. 109-112.

Herman, P. M. J. \& C. Heip, 1983b. The respiration of five brackish-water harpacticoid species. J. exp. mar. Biol. Ecol. 71: $249-256$.

Herman, P. M. J., C. Heip \& B. Guillemijn, 1984. Production of Tachidius discipes Giesbrecht 1881 (Copepoda: Harpacticoi- da). Mar. Ecol. Prog. Ser. 17: 271-278.

Herman, P. M. J., G. Vranken \& C. Heip, 1984. Problems in meiofauna energy-flow studies. Hydrobiologia 118: 21-28.

Kendall, M., 1976. Time-Series. 2nd Ed. Griffin \& Co.

Palmer, M., 1984. Invertebrate drift: behavioral experiments with intertidal meiobenthos. Mar. Behav. Physiol. 10: $235-253$.

Platt, T. \& K. Denman, 1975. Spectral analysis in ecology. Ann. Rev. Ecol. Syst. 6: 189-210.

Warwick, R. M., 1984. Species size distributions in marine benthic communities. Oecologia (Berl.) 61: 32-41. 